\title{
SIMÓN CASTELLANO, PERE Y ABADÍAS SELMA, ALFREDO. "LA PRISIÓN PROVISIONAL A ANÁLISIS: SU PROBLEMÁTICA APLICACIÓN PRÁCTICA Y EL SISTEMA DE INDEMNIZACIÓN POR DAÑO SACRIFICIAL". CIZUR MENOR (NAVARRA), ARANZADI, 2020, 374 PÁGS.
}

\author{
Javier Gilsanz Usunaga \\ Abogado Landwell-PwC \\ Profesor Asociado IE University
}

Es incuestionable que la tutela judicial cautelar es una materia cuyo estudio suscita un profundo interés del que no escapa la medida cautelar personal de prisión provisional, institución procesal salpicada, especialmente en los últimos tiempos, de cierta polémica. Y lo mismo se predica de otro asunto controvertido como es el sistema de indemnización por daño sacrificial. Ambas materias, estrechamente relacionadas entre sí, se han visto particularmente expuestas a la opinión pública con base en asuntos judiciales mediáticos que las han elevado a temas de actualidad, trascendiendo así el mero interés jurídico que las mismas suscitan por las incertidumbres legales que su aplicación comporta.

En términos generales la obra se encuentra estructurada en dos partes diferenciadas compuestas por ocho capítulos en total que encuentran sustento final en una bibliografía extensa y completa de las cuestiones estudiadas. El primer bloque relativo a la prisión provisional es abordado por el Profesor Alfredo Abadías y el segundo bloque relativo al sistema indemnizatorio del art. 294 LOPJ es tratado por el Profesor Pere Simón, autores que aportan su bagaje académico en esta materia a la obra.

La primera parte, desarrollada en cuatro capítulos, tiene como objeto el estudio de la medida cautelar personal de prisión provisional que puede decretarse en el curso de un proceso penal. La segunda parte del 
libro, desarrollada también en otros cuatro capítulos, tiene por objeto el estudio del sistema indemnizatorio por daño sacrificial contemplado en el art. 294 LOPJ.

Ambas partes de la obra, comprobará el lector nada más aproximarse al índice, ostentan una extensión similar lo que ayuda a presentar las materias tratadas en el libro con simetría y equilibrio, compartiendo también los bloques una sistemática y metodología general similar que desarrolla las cuestiones estudiadas con un mismo patrón expositivo: de lo general a lo particular y de lo teórico a lo práctico en cuanto que asuntos judiciales actuales les sirven de cierre. Finalmente, los autores terminan cada parte del libro con unas conclusiones personales sobre lo expuesto que tienen, lo percibirá rápidamente el lector, un claro carácter constructivo.

La primera parte de la obra se caracteriza por ser un estudio riguroso y pormenorizado de la prisión provisional sustentado por la jurisprudencia y la doctrina más relevante aplicables a esta medida cautelar de carácter personal. La sistemática concreta aplicada por el autor para esta primera parte de la obra proporciona una comprensión global de la materia estudiada y especialmente se caracteriza por su gran claridad en términos de exposición. Esta primera parte de la obra termina con un compendio de los asuntos judiciales más polémicos de los últimos años que supone un cierre acertado a la temática tratada previamente al permitir al lector observar el tratamiento judicial de las ideas expuestas anteriormente en procesos penales considerados mediáticos.

El primer capítulo estudia la prisión provisional desde su configuración como medida cautelar personal, detallando sus distintas funciones y abordando sus características esenciales, donde, especialmente, destaca la importancia de la motivación de la resolución judicial que acuerda la prisión provisional por ser limitativa de un derecho fundamental como es la libertad de la persona.

Los presupuestos de la prisión provisional son tratados en el segundo capítulo junto con las formas y la duración de la medida. En este sentido, destaca especialmente el tratamiento otorgado en la obra a dos cuestiones fundamentales y que siempre suscitan un gran interés en la comunidad jurídica: por un lado; la prisión provisional incomunicada y su injerencia en el derecho a la asistencia letrada y en el derecho a las comunicaciones. Y, por otro lado, la siempre controvertida cuestión de la duración de la prisión provisional.

El capítulo tercero se focaliza en el procedimiento de adopción de la medida cautelar de prisión provisional desde sus antecedentes históricos a los aspectos procedimentales más relevantes que vertebran la forma de adopción de la medida. En esta parte de la obra resulta especialmente interesante la mención relativa a cómo la decisión pactada entre el Juez y el Ministerio Fiscal podría atentar contra el derecho de defensa. 
El autor culmina la primera parte de la obra con una exposición de los asuntos judiciales más mediáticos e interesantes que afectan directamente a la institución de la prisión provisional. Ciertamente, casos judiciales como el asunto "Papeles de Bárcenas", "Operación Lezo", "Caso Pujol", "La manada", "Procés catalán” o el también famoso "Caso Rosell" encajan a la perfección en la obra para ofrecer una visión práctica final del tratamiento judicial de la medida cautelar de prisión provisional.

Tras haber abordado con éxito los aspectos conceptuales más relevantes en términos de presupuestos, fines, características, procedimiento de adopción de la prisión provisional y ofrecer una visión práctica mediante la exposición de asuntos judiciales notorios, la primera parte finaliza con la formulación por el Profesor Alfredo Abadías de unas conclusiones personales mediante las que pone de manifiesto, entre otras cuestiones, el dispar tratamiento judicial de la institución de la prisión provisional y la necesidad de revisar los preceptos legales que gobiernan esta medida cautelar.

La segunda parte de la obra se estructura en cuatro capítulos que tratan distintas cuestiones del daño sacrificial y el sistema de indemnización por prisión provisional injusta. Esta segunda parte, desde un punto de vista de sistemática y metodología, combina el tratamiento de distintas cuestiones desde un punto de vista dogmático con el tratamiento y análisis exhaustivo de la jurisprudencia más relevante en relación con la aplicación de los términos indemnizatorios recogidos en el art. 294 LOPJ.

En el capítulo quinto el Profesor Pere Simón aborda la prisión provisional injusta como supuesto concreto de daño sacrificial comenzando con un análisis histórico encomiable donde se abordan fundamentos relevantes en la materia como las distintas tesis personalistas, así como la aproximación funcionalista. A su vez, cobra una especial importancia en el capítulo la indemnización como medio de realizar una equidistribución del daño sacrificial de manera que la misma mitigue para la victima los efectos perjudiciales causados por la injerencia sacrificial.

Desde la premisa de la prisión provisional indebida o injusta como daño sacrificial, el capítulo sexto de la obra lleva a cabo un estudio profundo de la evolución de la doctrina jurisprudencial sobre la aplicación de lo dispuesto en el art. 294 LOPJ, a saber, la indemnización por daños y perjuicios por haber padecido una prisión provisional y posteriormente tenga lugar un pronunciamiento absolutorio.

En este análisis jurisprudencial cobra especial interés, en primer término, la Sentencia del Tribunal Constitucional 85/2019 de 19 de junio que declaró inconstitucionales ciertos incisos del art. 294.1 LOPJ y que se configura como el punto de partida expositivo de lo que posteriormente se analiza. Después, y precisamente al hilo de los interrogantes que plantea la mencionada sentencia, se expone el interesante debate del 
posible automatismo de la indemnización por los perjuicios causados conforme al citado artículo. Por último, finaliza este capítulo sexto planteando otro debate igual de interesante sobre los criterios para determinar la cantidad indemnizatoria acorde al art. 294.1 LOPJ.

Tomando como punto de partida la Sentencia del Tribunal Supremo de 10 de octubre de 2019 (RJ 2019, 3929) como primera resolución judicial que aplica el art. 294.1 LOPJ según los nuevos términos fijados por la Sentencia del Tribunal Constitucional 85/2019 antes mencionada, el capítulo séptimo lleva a cabo una revisión profunda de la practica judicial de la aplicación práctica de la indemnización recogida en el art. 294 LOPJ.

Ciertamente, durante este capítulo de la obra, el Profesor Pere Simón ofrece al lector una visión precisa, en primer término, de distintas sentencias del Tribunal Supremo posteriores a octubre de 2019 en relación con la configuración del quantum indemnizatorio. En segundo término, aborda distintos casos resueltos todos ellos en julio del año 2020 por la Sala de lo Contencioso-Administrativo de la Audiencia Nacional frente a denegaciones de concesión de indemnizaciones por prisión provisional injusta o indebida por parte del Ministerio de Justicia.

En muchas de las sentencias de la Audiencia Nacional analizadas en el capítulo concurre la existencia de un voto particular del Magistrado Díaz Fraile que es objeto de exposición detallada en la obra y que plantea cuestiones jurídicas prácticas no resueltas en relación con el art. 294 LOPJ (naturaleza de la indemnización, supuestos que deben encontrar cobertura bajo el citado artículo y cómo se determina la cantidad a indemnizar).

Finalmente, el capítulo termina con la formulación de unas interesantes conclusiones por el Profesor Pere Simón divididas en dos bloques diferenciados; por un lado, en relación con los supuestos que dan (o no) lugar a indemnización (entre otros, error invencible, casos de archivo definitivo y provisionales de la causa y sobreseimiento provisional de la causa). Y, por otro lado, en relación con la falta de criterios uniformes para fijar los conceptos que configuran la indemnización prevista en el art. 294 LOPJ señalando las propias contradicciones en las que incurren sobre este particular distintas sentencias del Tribunal Supremo y sentencias de la Audiencia Nacional.

La obra termina con el capítulo octavo donde el Profesor Pere Simón realiza algunas propuestas personales frente a las incertidumbres generadas por las cuestiones jurídicas relacionadas con el art. 294 LOPJ previamente analizadas en la obra. Las conclusiones formuladas ponen sin duda de manifiesto, primeramente, la necesaria intervención del legislador para dotar de mayor seguridad jurídica a cuestiones como el automatismo del derecho a obtener una indemnización en todos los supuestos. Y, del mismo modo, traen a colación la recomendada 
intervención del legislador para esclarecer los criterios aplicables para configurar el quantum indemnizatorio.

Indudablemente, nos encontramos ante una obra de actualidad en la que los autores no sólo consiguen suscitar en el lector un gran interés en la materia desde un punto de vista estrictamente académico, sino que también desde un punto de vista eminentemente práctico, pues la obra completa las nociones jurídicas teóricas expuestas con la visión práctica de su aplicación por parte de nuestros tribunales.

En definitiva, el Profesor Alfredo Abadías y el Profesor Pere Simón ofrecen una herramienta útil y necesaria para cualquier jurista que pretenda conocer con solvencia la medida cautelar de prisión provisional y el sistema indemnizatorio en supuestos de prisión provisional injusta o indebida. Adicionalmente, las conclusiones personales de los autores invitan a reflexionar al lector sobre posibles soluciones constructivas para esclarecer las incertidumbres legales que sobre las materias de estudio la obra revela.

Madrid, febrero 2021 